\title{
UMA EXPERIÊNCIA DE PRONTO ATENDIMENTO EM SAÚDE MENTAL COLETIVA
}

\author{
AN EXPERIENCE IN PRIMARY HEALTH \\ CARE IN A PUBLIC MENTAL HEALTH SERVICE
}

\author{
Abílio da COSTA-RosA* \\ Cristina Amélia LUZIO** \\ Márcia Cristina Schwarz MENDES ${ }^{\star \star *}$ \\ Patrícia FLOREZI ${ }^{\text {totut }}$
}

\begin{abstract}
RESUMO
Este artigo apresenta a reflexão sobre uma experiência de atendimento em grupo na porta de um serviço de Saúde Mental Coletiva de um município do Estado de São Paulo com 30 mil habitantes. Com a análise de dados referentes ao atendimento inicial desta instituição denominado "Pronto Atendimento" (PA), em especial as filas de espera em psiquiatria e em psicoterapia, considerou-se que o PA pode operar como um analisador, uma vez que é nesse atendimento que os usuários que procuram ajuda na instituição apresentam suas queixas e os seus pedidos de ajuda. É também a partir desse atendimento que a instituição, por meio de seus profissionais, oferece as possibilidades terapêuticas. A análise efetuada permitiu apontar que esse atendimento pode constituir ações que reforçam o paradigma psiquiátrico dominante ou ações que podem contribuir na construção do modelo psicossocial, partindo de mudanças da própria representação social da instituição, do sofrimento psíquico e dos recursos terapêuticos de cura.
\end{abstract}

Palavras-Chave: saúde mental, atenção primária, profissionais.

\section{ABSTRACT}

This paper presents a reflection on an experience learned from the primary health care provided by the staff of a public mental health service of a county

\footnotetext{
(*) Professor Assistente Doutor do Departamento de Psicologia Clínica da Universidade Estadual Paulista - Campus de Assis/SP, Doutor em Psicologia Clínica pela Universidade de São Paulo, Psicanalista e Analista Institucional.

(*) Professora Assistente Doutora do Departamento de Psicologia Clínica da Universidade Estadual Paulista - Campus de Assis/SP, Doutora em Saúde Coletiva pela Universidade Estadual de Campinas.

(*) Psicóloga, mestre em Psicologia pela Faculdade de Ciências e Letras da Universidade Estadual Paulista - Campus de Assis/SP. Endereço para Correspondência: R. Prof. Charles Fraga Moreira, 41 - Jardim Europa -Assis/SP CEP 19815-180 E-mail:marciaschz@uol.com.br

Psicóloga ex-aprimoranda do Programa de Aprimoramento em Saúde Mental e Saúde Pública da DIR VIII - Assis/SP.
} 
with about 30 thousand people in São Paulo State. Starting with the analysis of data of the primary health care provided by that institution, the so-called "Pronto Atendimento" (PA), focusing on patients waiting in line for referral to psychiatric and psychotherapeutic treatment, one suggests that PA may function as a support device since it is precisely in that primary health care service that patients make their complaints, ask for help and the institution, based on that service and its staff refers them lo a range of therapeutic treatment. The analysis of such data allowed us lo suggest that such primary health care service may include actions which reinforce the prevailing psychiatric paradigm or therapeutic actions which in turn may contribute to develop a psychosocial model taking into consideration changes effected in the very social representation of the institution, in the patient's psychic pain, and in the therapeutic resources available for cure.

Keywords:mental health, primary health care, primary care staff.

\section{INTRODUÇÃO}

O objetivo deste artigo é refletir sobre o atendimento no momento da chegada dos usuários a um serviço de Saúde Mental Coletiva, a partir da análise de experiências dos primeiros atendimentos, realizadas num Centro de Saúde de um município do interior do estado de São Paulo com, aproximadamente, 30.000 habitantes. Essa modalidade de atendimento é denominada Pronto Atendimento (PA) e tem como proposta o atendimento imediato no momento em que o usuário procura o serviço.

O PA é um espaço de escuta do usuário que deve e/ou pode englobar: a recepção, o acolhimento do usuário e seu encaminhamento para várias modalidades de atendimento. Tratase de um dispositivo terapêutico que faz fronteira com outros recursos disponíveis, tanto dentro da instituição quanto fora dela, em que é possível problematizar a relação entre oferta e demanda ${ }^{1}$ de tratamento (Oliveira, 2000).

Problematizar a relação entre a demanda e a oferta de tratamento, como aponta Oliveira (2000), significa pensar que, atrás dos sintomas ou pedidos que chegam ao PA, existe uma situação mais complexa. Nesse sentido, a demanda é diferente das queixas dos usuários que procuram ajuda nos serviços de Saúde
Mental Coletiva. A "falta" que sustenta a demanda subjaz à causa imediata explicitada na "encomenda". Portanto, além da queixa, que sustenta a "encomenda", devemos encontrar essa "falta", que pode nos remeter à estrutura de contrários da qual é expressão (Costa-Rosa,1987). Isto vai se refletir nas ofertas de tratamento que, diferentemente do tratamento sintomático, podem ter como modelo plano de ações sobre os fatores que causam os sintomas.

Neste trabalho, os principais, ainda que não únicos, recursos de que dispomos são a fala do usuário e a escuta de quem o acolhe. Esta escuta deve estar atenta ao dizer e não apenas ao dito, como nos aponta Door (1994), e deve procurar dar atenção a aspectos que se apresentam como os principais objetivos do PA: 0 ato de acolher, avaliar e encaminhar.

Acolher, como nos coloca Oliveira (2000), não no sentido de triar, dividir, ou classificar os sintomas das pessoas, mas sim receber bem, com atenção, tempo e disponibilidade, para que seja possível escutar evalorizar as particularidades de cada situação. "Trata-se de dar continência ao sujeito e não apenas ao seu quadro psicopatológico. Acolher significa promover condições para que aquele que sofre fale de seu mal-estar e de sua situação de vida, a fim de possibilitar uma avaliação consistente e coerente com aquilo

(1) Demanda, na perspectiva da análise institucional, é a falta que emerge da luta de contrários entre as forças produtivas e as relações de produção. O lado ou a contraface sob a qual essa falta, esse conflito se apresentará, é a "encomenda". 
que foi transmitido, muitas vezes, também pelos familiares" (Oliveira, 200, p. 34).

Avaliar vai além de realizar o diagnóstico, implica conhecermos e entendermos a situação do usuário para realizarmos um diagnóstico situacional. Isto significa colocar entre parênteses a doença e entrar em contato com a "existênciasofrimento” do usuário (Rotelli, 1990).

Esse momento serve também para avaliarmos não só os recursos dos usuários, mas também os recursos da instituição em que estamos inseridos, os recursos dos familiares, da comunidade; enfim, da rede de cuidados que circundam o usuário para melhor definirmos as próximas ações de cuidado. Portanto, significa colocarmos em cheque o paradigma psiquiátrico e pensarmos acerca do que significa, em termos práticos, tratar num outro paradigma - o modo psicossocial (Costa-Rosa, 2000).

Por fim, encaminhar exige, necessariamente, o acolhimento do usuário no sentido de se definir com clareza o objetivo, a função do encaminhamento e a finalidade do tratamento. $\mathrm{O}$ PA, assim concebido, objetiva muito mais reconstruir com o usuário que sofre uma nova perspectiva de vida, do que encaminhá-lo a um tratamento para reconduzi-lo a um suposto estado de saúde anterior ao sofrimento. Isto exige, entretanto, um reposicionamento por parte da instituição, uma vez que esta proposta requer também a revisão do tratamento oferecido.

Uma avaliação que leve em consideração a perspectiva ética delineada nos parágrafos anteriores possibilitará o encaminhamento com melhor resolução e eficácia. Vale lembrar que nem sempre se dispõe de recursos adequados para o atendimento, mas é importante ressaltar que $o$ ato de acolher, avaliar e encaminhar, nos moldes descritos até aqui, representa uma ruptura com o paradigma tradicional. Deixa-se de atender o indivíduo isolado, passa-se a exercitar uma visão holística do homem, capaz de levar em consideração a sua complexidade e, ao mesmo tempo, busca-se a ampliação dos dispositivos terapêuticos que substituem o modelo psiquiátrico dominante, cuja lógica ainda é centrada no tamponamento dos sintomas e na exclusão dos usuários por intermédio da internação e da medicação.

A discussão e a reflexão constantes sobre esse primeiro atendimento devem ser priorizadas nas instituições de Saúde Mental. O PA, apesar de ser fundamental, pode tornar-se uma rotina e, com isso, transformar-se em procedimento burocratizado. Esta rotina burocratizada nos serviços de Saúde Mental Coletiva supõe a reafirmação do papel do profissional competente, em que uma minoria detém o saber sobre tudo e todos da instituição e, portanto, pode vir a se constituir fonte de resistência a mudanças e à construção de novas possibilidades de atendimento. A burocratização do PA pode ser identificada como "administração de queixas", em que os usuários são "distribuídos", de acordo com as ofertas de atendimento existentes.

Como tal, o PA perderia a sua potência como um momento de criação, extremamente ativo e rico, pois os profissionais que o estariam realizando poderiam reduzir o PA a uma mera triagem, em que apenas se seleciona aqueles que supostamente necessitam de atendimento psiquiátrico dentre aqueles que carecem de atendimento psicológico ou de outros procedimentos. A redução do PA à triagem reafirma a cisão dos saberes, intensificando a fragmentação dos serviços e a fragmentação do usuário e produz um "... processo que termina por padronizar uma demanda específica, adequada ao perfil daquele determinado profissional de saúde..." (Levcovitz, 2000, p. 22). Portanto, realiza-se o caminho inverso ao que propomos, uma vez que não é a escuta da demanda que produz os esquemas teórico-técnicos mais adequados de tratamento.

\section{HISTÓRICO}

O PA do serviço de Saúde Mental Coletiva analisado foi implantado em março de 1998. Naquele momento, buscava-se, a partir da recepção, da triagem e do encaminhamento, atender à população com maior resolução e 
eficácia, assim como reorganizar os programas conforme necessidade da demanda.

Até então, na Saúde Mental, os atendimentos médicos ou psicológicos funcionavam como os demais atendimentos da unidade, as consultas eram agendadas em guichê, de acordo com o número de vagas fornecidas pelo profissional e/ou instituição.

O PA surgiu como proposta para tentar evitar os problemas que ocorriam com o agendamento prévio das consultas, pois as vagas semanais para psicoterapia e consulta psiquiátrica eram insuficientes. Esta situação gerava filas de usuários que se iniciavam de madrugada para tentar marcar o atendimento; conflitos freqüentes com o responsável pelo agendamento devido à insatisfação por não conseguirem vaga; venda de vagas na fila de espera pelos usuários; tráfico de influências para conseguir uma consulta na Saúde Mental ou diretamente com o psiquiatra. Muitas vezes, os usuários, em situações mais complexas e graves, precisavam recorrer ao atendimento emergencial do Pronto Socorro (PS) da Santa Casa. O PS, por sua vez, geralmente encaminhava o usuário em crise para internação psiquiátrica, pois não possuía recursos humanos e técnicos para propor outras formas de acolhimento e tratamento ao usuário em crise e/ou sofrimento psíquico.

O PA, em 1998, também tinha como objetivo contribuir para a redução das internações psiquiátricas, na medida em que priorizava 0 atendimento do usuário na rede extra-hospitalar, por meio de outras ações como: consulta psiquiátrica, uso de psicofármacos, retornos freqüentes à unidade, atendimento psicoterápico, oficinas terapêuticas, orientação a familiares e intervenções nos espaços sociais do usuário.

No entanto, no final de 1999, observou-se a reprodução dos mesmos problemas entre a procura e oferta de serviços. Novamente, a equipe deparou-se com uma significativa demanda por atendimento que não era absorvida pelo serviço. Se, por um lado, o usuário ao procurar tratamento na Saúde Mental era prontamente recepcionado/avaliado por um técnico da equipe, por outro lado, o encaminhamento muitas vezes acabava apenas aumentando a fila de espera para atendimento psicoterápico e/ou psiquiátrico. Constatava-se que a procura pelos serviços era maior que a oferta de atendimentos pelo programa, pois o critério para chamar novos usuários era a existência de vagas oferecidas pelos diferentes profissionais, não havendo previsão de tempo para a convocação dos mesmos. A espera poderia ser de dias, semanas ou meses e verificavam-se, freqüentemente, muitos abandonos ou desistências ao se chamar os usuários da fila de espera.

Essa situação provocou discussões na equipe. Surgiram vários questionamentos, tais como:

- Quais eram os casos que ficavam em lista de espera? Qual o sexo, idade, queixa?

- Os usuários em lista de espera ainda precisavam, de fato, do atendimento que aguardavam?

- O longo tempo de espera fazia com que o usuário buscasse resolver suas questões por outros meios?

- A equipe estava conseguindo perceber as necessidades de reorganização das ações terapêuticas em consonância com a diversidade e gravidade das demandas?

- As ofertas de atendimento respondiam às expectativas dos usuários?

- Como se deveria agir com os usuários que buscavam e insistiam de várias formas em passar por atendimento psiquiátrico e medicamentoso, apesar das avaliações e dos outros encaminha-mentos feitos pelos profissionais do PA?

- Poder-se-ia negar o que os usuários solicitavam, sendo estes sujeitos de direitos?

Uma outra situação constatada foi que muitos usuários, atendidos em PA, já estavam em tratamento na Saúde Mental e não se encontravam numa situação de crise ou recaída. Embora essas situações fossem consideradas como intercorrências, observou-se que esses 
usuários retornavam porque não tinham recebido medicação em quantidade suficiente até sua consulta de retorno. Em contrapartida, verificou-se que muitos usuários, ao chegarem ao PA, somente conheciam e reconheciam como tratamento em Saúde Mental o atendimento psiquiátrico, mas, depois do acolhimento no PA, tornaram-se receptivos a outras formas de atendimento que não o tratamento médico/medicamentoso, embora esta fosse a justificativa inicial para a procura do serviço.

No que se refere às internações psiquiátricas, constatou-se que o PA era resolutivo, pois nesse espaço foi possível viabilizar o vínculo com os usuários, em situações graves e, conseqüentemente, um atendimento diversificado e mais eficaz como, por exemplo, retorno, escuta diária na unidade e intervenção familiar.

Outro aspecto discutido pela equipe foi o encaminhamento dos usuários, em situações aparentemente menos graves, para "fila de espera" em psiquiatria e em psicologia.

\section{PROCEDIMENTO METODOLÓGICO}

A partir dos questionamentos da equipe acerca do PA, buscou-se conhecer as filas de espera em psiquiatria e em psicologia existentes no serviço. Para isso, foi realizado o levantamento dos prontuários dos usuários inscritos nas duas filas de espera. Após leitura detalhada dos registros relativos aos atendimentos em Saúde Mental contidos em cada prontuário, os dados necessários para a análise foram destacados, sistematizados e processados em tabelas, sendo que as categorias utilizadas na sistematização das queixas dos usuários identificadas nas duas listas de espera foram construídas a partir das ocorrências dos sinais e sintomas descritos nos prontuários.

Após análise e discussão dos dados referentes às filas de espera em psiquiatria $e$ psicologia, foi iniciada, em agosto de 2000, uma experiência de PA em grupo, sob a responsa- bilidade de dois profissionais da equipe. Nesta nova modalidade de PA, todos os usuários que chegavam à Unidade de Saúde procurando tratamento em Saúde Mental eram atendidos em grupo. Este atendimento inicial contemplava não apenas a entrevista inicial, mas também quantos retornos fossem necessários, de modo que possibilitassem o acolhimento e melhor entendimento da demanda para possíveis encaminhamentos. A escolha dessa modalidade de atendimento se justificou, pois o grupo é um dispositivo capaz de propiciar encontros, escutas, trocas e a reflexão coletiva sobre possibilidades e não soluções imediatas de problemas. Portanto, essa proposta foi permeada pela concepção de que o acolhimento do usuário que chega ao serviço de Saúde Mental deve propiciar contato com a dimensão subjetiva dos seus sintomas, bem como com a implicação do sujeito que sofre.

\section{DISCUSSÃO E ANÁLISE}

\section{Fila de espera em psiquiatria}

O estudo realizado a partir dos prontuários dos usuários que estavam esperando consulta psiquiátrica mostrou que, em fevereiro de 2000 , aguardavam atendimento em psiquiatria 59 usuários: 28 deles tinham passado pelo PA no ano de 1999; outros 29 nos meses de janeiro a fevereiro de 2000; e, no caso de dois usuários, não havia informações sobre a data do PA.

Tabela 1.Dados sociodemográficos - sexo - dos usuários da fila de espera da psiquiatria na instituição, em fevereiro de 2000.

\begin{tabular}{rcc}
\hline SEXO & No & $\%$ \\
\hline Homens & 24 & 40,7 \\
Mulheres & 35 & 59,3 \\
& 59 & 100 \\
\hline
\end{tabular}


Tabela 2. Dados sociodemográficos - idade - dos usuários da fila de espera da psiquiatria na instituição, em fevereiro de 2000.

\begin{tabular}{lcc}
\hline FAIXASETÁRIAS & No $^{\circ}$ & $\%$ \\
\hline 10 a 20 anos & 3 & 5,1 \\
21 a 50 anos & 39 & 66,1 \\
51 a 70 anos & 14 & 23,7 \\
+ de 71 anos & 3 & 5,1 \\
\hline
\end{tabular}

Tabela 3. Dados sociodemográficos - estado civil - dos usuários da fila de espera da psiquiatria na instituição, em fevereiro de 2000.

\begin{tabular}{lcc}
\hline \multicolumn{1}{c}{ ESTADO CIVIL } & $\mathbf{N}^{\mathbf{0}}$ & $\%$ \\
\hline Solteiro ou Separado & 12 & 20,3 \\
Casado ou Amasiado & 40 & 67,8 \\
Viúvo & 6 & 10,2 \\
Outros & 1 & 1,7 \\
\hline
\end{tabular}

Tabela 4.Dados sociodemográficos - condição de ocupação - dos usuários da fila de espera da psiquiatria na instituição, em fevereiro de 2000.

\begin{tabular}{lcc}
\hline CONDIÇÃO DE OCUPAÇÃo & No & $\%$ \\
\hline P. domésticas & 9 & 15,3 \\
Trabalhador rural & 8 & 13,5 \\
Motorista & 3 & 5,1 \\
Desempregado & 5 & 8,5 \\
Aposentado ou afastado & 5 & 8,5 \\
Outros & 8 & 13,5 \\
Não consta informação & 21 & 35,6 \\
\hline
\end{tabular}

Tabela 5. Dados referentes à origem do encaminhamento dos usuários da fila de espera da psiquiatria na instituição, em fevereiro de 2000.

\begin{tabular}{lcc}
\hline TIPODE ENCAMINHAMENTO & No & \% \\
\hline Espontâneo & 23 & 38,9 \\
Médico & 21 & 35,6 \\
Funcionário da instituição & 3 & 5,1 \\
Psiquiatra de outra instituição & 1 & 1,7 \\
Judiciário & 1 & 1,7 \\
Psicólogo de consultório & 1 & 1,7 \\
Centro de recuperação & 1 & 1,7 \\
PS da Sta Casa & 1 & 1,7 \\
Não consta & 7 & 11,9 \\
\hline
\end{tabular}

Tabela 6. Dados referentes ao tipo de tratamento recebido anteriormente pelos usuários da fila de espera da psiquiatria na instituição, em fevereiro de 2000.

\begin{tabular}{lcc}
\hline TIPO DE TRATAMENTO & No & $\%$ \\
\hline Não tratou anteriormente & 36 & 61,0 \\
Tratamento psiquiátrico & 13 & 22,1 \\
Psicoterapia individual & 4 & 6,8 \\
Psicoterapia de grupo & 5 & 8,4 \\
Não conta & 1 & 1,7 \\
\hline
\end{tabular}

Tabela 7. Dados referentes à internação psiquiátrica dos usuários da fila de espera da psiquiatria na instituição, em fevereiro de 2000.

\begin{tabular}{lcc}
\hline INTERNAÇÃO PSIQUIÁTRICA & No & $\%$ \\
\hline Não & 40 & 67,8 \\
Sim, hospital psiquiátrico & 9 & 15,2 \\
Sim, hospital geral & 6 & 10,2 \\
Não conta & 4 & 6,8 \\
\hline
\end{tabular}


Tabela 8. Dados referentes à queixa dos usuários da fila de espera da psiquiatria na instituição, em fevereiro de 2000.

\begin{tabular}{lcc}
\hline \multicolumn{1}{c}{ QUEIXA } & No & $\%$ \\
\hline Depressivas & 13 & 22,0 \\
Depressivas, com convulsões & 1 & 1,7 \\
Depressivas, com distúrbios de sono & 1 & 1,7 \\
Depressivas, com distúrbio de alimentação & 1 & 1,7 \\
Depressivas, com ambos os distúrbios & 1 & 1,7 \\
Depressivas, com idéias suicidas & 3 & 5,1 \\
De isolamento social, perturbações do sono & 1 & 1,7 \\
Nervosismo, ansiedade, excitabilidade & 6 & 10,1 \\
Depressivas, com distúrbios do pensamento & 3 & 5,1 \\
De distúrbios do pensamento & 1 & 1,7 \\
De distúrbios da percepção & 3 & 5,1 \\
De problemas emocionais associadas com tireóide & 2 & 3,4 \\
Ligadas ao alcoolismo & 5 & 8,5 \\
Ligadas a drogadição & 2 & 3,4 \\
Do tipo conversivo & 5 & 8,5 \\
De agressividade associada com convulsões & 1 & 1,7 \\
De natureza fóbica & 1 & 1,7 \\
Difusas & 9 & 15,2 \\
\hline
\end{tabular}

\section{Fila de espera da psicologia}

A análise dos prontuários de usuários que aguardavam atendimento psicológico em junho de 2000 indicou que 49 usuários esperavam ser chamados para tratamento.

A comparação dos dados sociodemográficos dos usuários em fila de espera por atendimento psiquiátrico (tabelas 1 a 4) com os dos usuários em fila de espera por atendimento psicoterápico (tabela 9 a 12) mostrou que não houve diferenças na clientela que aguardava por atendimento psiquiátrico e por psicoterapia. Quanto ao sexo, verificou-se que predominavam mulheres, sendo $59,3 \%$ na fila de espera da psiquiatria e $63,3 \%$ na fila de espera de psicoterapia. A maioria delas se encontrava, nas duas listas, na faixa etária entre 21 e 50 anos, sendo $66,1 \%$ do total na lista da psiquiatria e $63,3 \%$ na lista de psicoterapia. Quanto ao estado civil, também predominou, nas duas listas, maior porcentagem de usuários casados ou amasiados: $67,8 \%$ na lista de psiquiatria e $44,9 \%$ na de psicoterapia. Sobre a condição de ocupação, verificou-se que em $35,6 \%$ dos casos da lista da psiquiatria e em $20,4 \%$ da lista de psicoterapia não constavam informações sobre atividades de trabalho. Também se observou que $15,3 \%$ dos usuários da lista de psiquiatria e $20,4 \%$ da lista de psicoterapia declararam não trabalhar fora de casa. 
Tabela 9. Dados sociodemográficos - sexo - dos usuários na fila de espera por atendimento psicoterápico na instituição, em junho de 2000.

\begin{tabular}{rcc}
\hline SEXO & No & $\%$ \\
\hline Homens & 18 & 36,7 \\
Mulheres & 31 & 63,3 \\
& 49 & 100 \\
\hline
\end{tabular}

Tabela 10. Dados sociodemográficos - idade - dos usuários na fila de espera por atendimento psicoterápico na instituição, em junho de 2000.

\begin{tabular}{lcc}
\hline FAIXASETÁRIAS & No & $\%$ \\
\hline 10 a 20 anos & 8 & 16,3 \\
21 a 50 anos & 31 & 63,3 \\
51 a 70 anos & 9 & 18,4 \\
+ de 71 anos & 1 & 2,0 \\
\hline
\end{tabular}

Tabela 11. Dados sociodemográficos - estado civil - dos usuários na fila de espera por atendimento psicoterápico na instituição, em junho de 2000.

\begin{tabular}{lcc}
\hline \multicolumn{1}{c}{ ESTADO CIVIL } & No & $\%$ \\
\hline Casado ou Amasiado & 22 & 44,9 \\
Solteiro & 16 & 32,6 \\
Separado ou divorciado & 4 & 8,2 \\
Viúvo & 5 & 10,2 \\
Outros & 2 & 4,1 \\
\hline
\end{tabular}

Foi na comparação dos dados referentes à condição de tratamento dos usuários das filas de espera por atendimento psiquiátrico e psicoterápico que algumas diferenças puderam ser observadas ${ }^{2}$. Dentre elas destacou-se um maior número de usuários da fila de espera da psiquiatria.

Esse dado suscitou algumas indagações: Poderia ser visto como um reflexo do paradigma psiquiátrico? A percepção da clientela quanto à oferta institucional seria a de atendimento psiquiátrico, levando à maior procura por este atendimento?

Em relação à fila de espera da psiquiatria, podia-se constatar que a oferta semanal de consulta psiquiátrica para casos novos propiciava um fluxo mais ágil dos atendimento dos usuários nela incluídos. No que se referia à fila de espera para atendimento psicoterápico, a situação era diversa. Embora o número de usuários desta fila de espera fosse menor, o fluxo de atendimento também era, uma vez que os usuários eram atendidos de acordo com a disponibilidade de agenda dos profissionais.

No que se referia à maneira como os usuários chegavam àquele serviço, pôde observarse que, nas duas listas de espera (tabelas 5 e 13), a maior porcentagem dos usuários procurou o serviço espontaneamente, $38,9 \%$ na lista da psiquiatria e $57,1 \%$ na lista de espera da psicoterapia. Em seguida, a maior porcentagem foi encaminhada por médicos, $35,6 \%$ na fila de espera da psiquiatria e $28,5 \%$ na fila de espera de psicoterapia. Esta tendência também se reproduziu nos encaminhamentos para a psiquiatria realizados por outras instituições e outros profissionais, o que parece refletir uma representação nos diversos segmentos sociais de que o tratamento na Saúde Mental é restrito ao atendimento médico.

Outro dado interessante foi que $61 \%$ dos usuários em fila de espera por atendimento psiquiátrico não tinham tido tratamento anterior na Saúde Mental da instituição e 67,8\% não tinham história de internações psiquiátricas (Tabelas 6 e 7). Também na fila de espera por atendimento psicoterápico, $59,2 \%$ dos usuários não tinham história anterior de tratamento na

(2) É importante destacar que as duas listas de espera se referiam a períodos diferentes. A lista de espera da psiquiatria foi analisada em fevereiro de 2000 e a da psicoterapia em junho de 2000. 
Saúde Mental, mas o mesmo número de usuários $(59,2 \%)$ fazia uso de medicações psiquiátricas, freqüentemente benzodiazepínicos prescritos por clínicos (Tabelas 13 e 15).

Tabela 12. Dados sociodemográficos - condição de ocupação - dos usuários da fila de espera por atendimento psicoterápico na instituição, em junho de 2000.

\begin{tabular}{lcc}
\hline \multicolumn{1}{c}{ CONDIÇÃODEOCUPAÇÃo } & $\mathbf{N}^{\mathbf{0}}$ & $\%$ \\
\hline P. domésticas & 10 & 20,4 \\
Comerciario/auton/informal & 7 & 14,3 \\
Funcionário público & 5 & 10,2 \\
Empregado doméstico & 4 & 8,2 \\
Desempregado & 4 & 8,2 \\
Trabalhador rural/agricultor & 4 & 8,2 \\
Estudante & 3 & 6,1 \\
Aposentado ou afastado & 2 & 4,0 \\
Não consta informação & 10 & 20,4 \\
\hline
\end{tabular}

Tabela 13. Dados referentes à origem do encaminhamento dos usuários da fila de espera por atendimento psicoterápico instituição, em junho de 2000.

\begin{tabular}{lcr}
\hline \multicolumn{1}{c}{ TIPODE ENCAMINHAMENTO } & No & $\%$ \\
\hline Espontâneo & 28 & 57,1 \\
Médico & 14 & 28,6 \\
Conselho Tutelar & 1 & 2,1 \\
Assistência social & 1 & 2,1 \\
Não consta & 5 & 10,2 \\
\hline
\end{tabular}

Tabela 14. Dados referentes ao tipo de tratamento recebido anteriormente pelos usuários da fila de espera da psiquiatria na instituição, em fevereiro de 2000.

\begin{tabular}{lcc}
\hline \multicolumn{1}{c}{ TIPODE TRATAMENTO } & No & $\%$ \\
\hline Não tratou anteriormente & 29 & 59,2 \\
Tratamento psiquiátrico & 9 & 18,4 \\
Psicoterapia & 11 & 22,4 \\
\hline
\end{tabular}

Tabela 15. Dados referentes ao uso de medicação psiquiátrica dos usuários da fila de espera por atendimento psicoterápico na instituição, em junho de 2000.

\begin{tabular}{lcc}
\hline $\begin{array}{c}\text { USO DEMEDICAÇÃo } \\
\text { PSIQUIÁTRICA }\end{array}$ & $\mathbf{N}^{\circ}$ & $\%$ \\
\hline Não & 29 & 59,2 \\
Sim & 20 & 40,8 \\
\hline
\end{tabular}

Ainda quanto ao tipo de atendimento oferecido pelo serviço, pôde-se observar, por meio da análise dos dados da lista de espera de psicologia, o predomínio da oferta de atendimento psicoterápico individual (63,2\%), o que parece mostrar um modelo de atenção pautado na escuta individual. Apesar de se tratar de um serviço de Saúde Mental Coletiva, o atendimento em grupo representou $12,2 \%$ das ofertas (Tabela 14 ).

Em relação às queixas, pode-se verificar na Tabela 8 que, na fila de espera da psiquiatria, as 
mais freqüentes foram: depressiva $(28,8 \%)$ e associadas a distúrbios do pensamento e da percepção (11,9\%). Jáas queixas predominantes na fila de espera de psicoterapia, conforme mostra a Tabela 16, foram: nervosismo, irritabilidade e ansiedade (36,7\%), depressivas (20,5\%), difusas $(10,2 \%)$ e associadas a distúrbios do pensamento e da percepção $(8,3 \%)$.

Tabela 16. Dados referentes à queixa dos usuários da fila de espera da psiquiatria na instituição, em fevereiro de 2000.

\begin{tabular}{lcc}
\hline \multicolumn{1}{c}{ QUEIXA } & No & $\%$ \\
\hline Nervosismo/irritabilidade/ansiedade & 11 & 22,4 \\
Nerv/irritab/ansiedade c/ perturb. sono e aliment. & 7 & 14,3 \\
Depressivas & 6 & 12,3 \\
Depressivas com perturbações do sono & 2 & 4,1 \\
Depressivas com perturb. sono e alimentação & 2 & 4,1 \\
Distúrbios da percepção & 4 & 8,2 \\
Angústia/ansiedade com perturb. sono e aliment. & 1 & 2,0 \\
Ansiedade c/ perturbações alimentares & 1 & 2,0 \\
De natureza fóbica & 2 & 4,1 \\
Conflitos familiares & 1 & 2,0 \\
Conflitos conjugais & 2 & 4,1 \\
Conflitos afetivos & 1 & 2,0 \\
Do tipo conversivo & 2 & 4,1 \\
Ligadas ao alcoolismo & 1 & 2,0 \\
Ligadas a drogadição & 1 & 2,0 \\
Difusas & 5 & 10,2 \\
\hline
\end{tabular}

As principais questões levantadas em 1999, por ocasião da discussão dos problemas encontrados na realização do PA, centravam-se em como estava sendo realizada a escuta, como se concebia a demanda e como eram feitos os encaminhamentos. Parecia-nos que os encaminhamentos do PA eram independentes da leitura da demanda, pautando-se mais pelas queixas e sintomas apresentados pelos usuários. As problemáticas que levavam o PA a encaminhar para atendimento psiquiátrico eram, principalmente, as queixas depressivas e para o atendimento psicoterápico, as queixas de nervosismo, irritabilidade e ansiedade.

Outro aspecto que pode ser observado em relação às duas listas de espera foi a pequena ocorrência de queixas ligadas ao uso abusivo de substâncias químicas, reafirmando que, por um lado, por meio do PA, estas problemáticas pareciam estar sendo acolhidas e inseridas em programas terapêuticos; no entanto, a existência, mesmo que pequena, de usuários com essas queixas em fila de espera por atendimento psiquiátrico e psicoterápico contrariava a proposta inicial de PA que pretendia buscar maior resolução diante das problemáticas mais graves ou complexas.

A partir da análise das filas de espera, observou-se que o PA nessa instituição estava reproduzindo, no atendimento extra-hospitalar, o modelo manicomial por intermédio da construção de um outro tipo de "depósito de usuários". Este era mais sutil, mas evidenciava que a criação de uma nova estrutura de atendimento, com novo 
nome e funcionamento institucional, não era a garantia de atendimento com qualidade e eficácia para os usuários desse serviço de Saúde Mental Coletiva.

Nesse sentido, o PA apenas tinha conseguido protelar o momento de incluir o usuário na fila de espera por um atendimento em Saúde Mental. Ele não era mais colocado na fila de espera, pelo setor de agendamento do Centro de Saúde, no momento de sua chegada ao equipamento. Sua inclusão na fila de espera passou a ocorrer depois do(s) primeiro(s) atendimento(s) no PA. Instituiu-se, portanto, não um Pronto Atendimento, em termos de recepção, acolhimento e inclusão do usuário em novas modalidades terapêuticas substitutivas à internação psiquiátrica, mas um serviço de recepção e triagem dos usuários para os atendimentos psiquiátricos e psicoterápicos já existentes.

\section{PA em grupo: uma proposta possível?}

OPA em grupo visava, por um lado, entender melhor as queixas e/ou necessidades dos usuários, dar acolhimento e/ou continência imediata e também, por outro lado, propunha-se a criar condições de discussão, na equipe, da situação dos usuários concomitantemente ao processo de PA, com objetivo de rever as ações assistenciais existentes e de construir outras intervenções que se mostrassem necessárias. Enfim, esta proposta de PA buscava "desmontar" as filas de espera e propiciar uma prática coletiva de problematização acerca das demandas iniciais trazidas pelos usuários como motivo da busca do atendimento.

Durante o desenvolvimento dessa experiência, foi possível constatar que por meio do grupo muitas questões eram colocadas pelos usuários. Nele ocorriam vários movimentos como, por exemplo: enfrentar o desafio de falar e mostrar a dor diante dos outros, escutar a dor alheia, poder indagar-se acerca de si, dos outros e do mundo. Também eram discutidas as especificidades do tratamento em Saúde Mental, assim como se procurava esclarecer as possibilidades do atendimento oferecido na instituição e a necessidade de implicação dos usuários com o mesmo.

O PA em grupo ocorria uma vez por semana ${ }^{3}$, sem seleção prévia dos usuários que buscavam o atendimento naquele dia. Num primeiro momento, os usuários eram esclarecidos quanto à proposta de atendimento grupal para que as pessoas pudessem decidir participar ou não. Aqueles que não aceitassem participar do grupo poderiam voltar à instituição em outros dias e períodos de PA para atendimento individual. Observou-se que "poucos" se recusavam a permanecer no grupo.

No início do grupo era proposto aos participantes que dissessem os motivos pelos quais estavam procurando atendimento e o que esperavam do mesmo. Essa abordagem propiciou aos usuários, em vários momentos, a identificação com seus companheiros do grupo, já que verbalizavam sintomas e problemas que eram, às vezes, compartilhados com outros integrantes do grupo. Permitiu também discussões acerca das semelhanças e diferenças entre suas angústias, sintomas e forma de lidar com o sofrimento que naquele momento os invadia, assim como sobre o que acreditavam estar relacionado com a causa e/ou solução dos mesmos. A partir dos vários encontros, em que se buscava conhecer melhor as problemáticas dos usuários, levantar no grupo questões sobre o sofrimento psíquico e agenciar os recursos de que a instituição dispunha, os profissionais apresentavam a devolutiva e a proposta de tratamento. Tal procedimento era realizado no grupo e passível de modificação, na medida em que procurava contemplar algumas solicitações e sugestões do usuário no seu atendimento na instituição.

(3) O Pronto Atendimento, nesta instituição, ocorria de segunda a sexta-feira e, em cada período, (manhã/tarde) havia um técnico de referência responsável pelos atendimentos. Esta forma de PA continuava concomitan-temente à modalidade grupal que era realizada uma vez por semana. 
Implementar essa experiência significou uma ruptura com o modelo de atendimento psíquico pautado pela escuta individualizada, que era a forma de atendimento realizado no PA até então. Romper com uma estrutura de atendimento, já instituída naquele serviço de Saúde Mental, produziu vários tipos de movimentos na equipe, principalmente resistências. Estas apareceram, muitas vezes, sob a forma de preocupações técnicas e até mesmo éticas como, por exemplo, a necessidade de sigilo profissional no atendimento do sofrimento psíquico. A proposta também causou incômodo nos profissionais de apoio, que, freqüentemente, questionavam essa modalidade de atendimento, em especial a necessidade de sigilo profissional dos problemas dos usuários. É importante destacar também que, com essa nova forma de PA, não houve encaminhamento para filas de espera, nem encaminhamento para internações.

\section{CONSIDERAÇÕES FINAIS}

É preciso considerar que o Pronto Atendimento como prática assistencial na porta dos serviços de Saúde Mental pode ser decisivo para o estabelecimento do vínculo do usuário com o tratamento. Nesse sentido, a chegada do usuário ao serviço já estaria em si atravessada pelas questões que se colocam para o tratamento como um todo (Tenório, 2000). Este momento é de suma importância para que o usuário possa sentir-se acolhido pela e na instituição. Tal contato refletirá em todo o percurso do atendimento, pois o momento em que uma pessoa procura ajuda, via encaminhamento, trazida por terceiros ou por demanda espontânea, é o momento em que os recursos do indivíduo utilizados até então não estão sendo suficientes para lidar com seus conflitos e, portanto, com seu sofrimento. São pessoas oriundas de diferentes regiões, diferentes estratos sociais e culturais que se apresentam com um ponto bastante comum: o intenso sofrimento psíquico e a busca por ajuda imediata.

Num primeiro momento, pode-se constatar que, muitas vezes, os usuários aparecem com uma demanda somática, poliqueixosa e/ou inespecífica, procurando "... Saber qual o mal que os ataca ou sofrem, do que precisam para livrar-se de sua doença, daquilo que lhe dói ... Dificilmente a demanda é psicológica, mas sim médica" (Luzio, 1988, p. 49).

Há pessoas que transformam seus sofrimentos psíquicos em somatizações e parecem alienar-se de seu universo psíquico, não associando seus sintomas a qualquer aspecto ou situação de suas vidas. O imaginário popular, que circunscreve o saber médico como único saber capaz de livrá-lo de seu sofrimento, tornase um analisador ${ }^{4}$ importante para se compreender as listas de espera existentes nos serviços de saúde mental. Esse saber médico, na maioria das vezes com fórmulas medicamentosas, poupa o sujeito da implicação subjetiva no tratamento. Sendo assim, trabalhar com esse imaginário tornou-se de grande importância, pois a desmitificação do tratamento se transformou em aliado constante no decurso do mesmo. Esse imaginário não é privilégio apenas dos usuários, pelo contrário, pertence à própria instituição de saúde. Nesta instituição os usuários não eram encaminhados para o tratamento no serviço de Saúde Mental, mas sim para a psiquiatria, reafirmando assim o modelo médico-psiquiátrico dominante.

Outro analisador que constantemente apareceu no desenvolvimento da proposta de trabalho, também presente no imaginário popular e na subjetividade dos sujeitos encaminhados ou que procuravam o atendimento, foi a percepção a respeito da concepção de Saúde Mental, da loucura e de seu tratamento. Constatou-se que era necessário abordar 'no' e 'com' o grupo o motivo do encaminhamento, da procura, como

(4) O sentido do termo analisador utilizado refere-se à conceituação de analisador espontâneo ou natural proposto por Baremblitt (1992). Para o autor, o analisador espontâneo ou natural "são analisadores de fato, produzidos 'espontaneamente' pela própria vida histórico-social-libidinal e natural, como resultado de suas determinações e da sua margem de liberdade." (Baremblitt, 1992, p. 152). 
se sentiam ao serem encaminhados à Saúde Mental, como eles se percebiam nesse espaço que geralmente os colocava em intensa angústia.

A demanda de "ser louco ou não ser, eis a questão" aparece com muita intensidade e não deve ser negligenciada no PA. Portanto, este trabalho, requer uma implicação por parte dos profissionais que atuam no PA para que se possa oferecer ao usuário um espaço de escuta, em que ele se sinta acolhido e possa entrar em contato e conhecer o seu desamparo. Em síntese, um espaço que "... pudesse freqüentar quantas vezes fossem necessárias para clarear ou construir uma demanda de tratamento... Trata-se de promover na fala do paciente a emergência de sua singularidade" (Oliveira, 2000, p. 32).

Esse foi um dos objetivos da experiência de PA em grupo. Procurou-se fazer com que 0 sujeito e o grupo, na emergência de sua singularidade, tomassem para si sua responsabilidade no decurso de sua "existênciasofrimento", implicando o sujeito no que lhe dissesse respeito, procurando junto com o grupo compreender o que realmente se passava nas falas trazidas, quais seus desejos, demandas. Além disso, buscou-se propiciar caminhos, facilitar o processo de quebra de resistências, desmitificar a loucura de modo a possibilitar ao sujeito tornar-se ator principal no processo terapêutico. Este, por sua vez deveria provocar "um reposicionamento do sujeito de tal modo que ele, em vez de apenas sofrer os efeitos desses conflitos, passasse a se reconhecer, por um lado, também como um dos agentes implicados nesse 'sofrimento' e, por outro, como agente da possibilidade de mudanças" (Costa-Rosa, 2000, p.155).

Tal posicionamento coloca-se como "uma das inversões básicas dos meios de tratamento", levando-se em conta o paradigma psiquiátrico do modo asilar em relação ao modo psicossocial, fazendo com que o grupo saia da postura de grupo assujeitado para assumir uma nova identidade, a de grupo sujeito (Costa-Rosa, 2000, p.155).

A possibilidade dos retornos em Pronto Atendimento também permitiu rever os enca- minhamentos para atendimentos psicoterápicos. Às vezes a demanda de análise ou de psicoterapia só pode ser verificada ao longo de entrevistas preliminares (Quinet, 2000). Num primeiro momento, ao buscar o atendimento, o sujeito vai falar de suas queixas, de seus sintomas, sendo necessário expressá-los para poder subjetiválos e buscar outras dimensões dos mesmos e, talvez, outras formas de expressão.

Os grupos de PA não se constituíram como entrevistas preliminares de uma análise, mas neles as queixas, que chegaram como motivo para a procura de ajuda, puderam ser questionadas. Ao buscar atendimento numa instituição para tratar seu sofrimento psíquico, o usuário faz uma escolha a partir da expectativa de obter a resposta que Ihe pareça adequada para o seu problema. A possibilidade de produzir mudanças nesta expectativa está centrada nas relações transferenciais que se produzem a partir da demanda apresentada.

$O$ atendimento realizado no PA, ao buscar em algum momento promover uma mudança na relação do usuário com aquilo que o faz sofrer, supõe uma concepção psicanalítica do sofrimento psíquico em que o sintoma tem um sentido ligado à existência do sujeito que sofre e uma operação deve ser feita quanto à demanda. Esse trabalho de pensar sobre a doença, sobre o sofrimento que ela causa e que também move em direção à procura de ajuda, leva algum tempo. Na medida em que o usuário tem no PA a possibilidade de reavaliar sua relação com a doença, talvez seja possível ele se responsabilizar por seu tratamento.

Porém, para que a demanda possa ser interrogada é necessário que, nesse trabalho preliminar, a escuta se volte inicialmente para o conhecimento do que o usuário traz sobre seu sofrimento. Trata-se de uma ação fundada no desejo de saber, na medida em que alguns desejam saber o que se passou com eles e articulam a queixa a algum contexto de sua existência. Nesse sentido, o PA pode realizar um atendimento preliminar a qualquer encaminhamento e avaliar, ou talvez construir, a demanda por um tratamento. 
A transformação da queixa em "questão" está sujeita ao do endereçamento realizado em relação ao profissional e à instituição, dependendo, portanto, da transferência. No PA, freqüentemente, o endereçamento a ser construído remete a outro profissional ou a outra instituição e, portanto, é necessário um manejo específico da transferência para que ela possa continuar se transferindo.

A transferência que se estabelece no PA é contingente, com um endereçamento inicial. A partir daí, a forma como o usuário é escutado, as intervenções feitas, os caminhos apontados, podem ser silenciadores da dimensão subjetiva ou constituir uma tentativa de abrir essa dimensão para os usuários dos serviços de Saúde Mental.

Essa metodologia de trabalho pode provocar uma maior resolução no próprio PA. Na experiência, as queixas situacionais eram resolvidas no próprio grupo. Sujeitos que necessitavam de tratamento em Saúde Mental eram encaminhados não mais para listas de espera, mas para profissionais, dando assim seqüência ao atendimento iniciado no ato de acolher. Durante seis meses desse trabalho nenhum caso foi encaminhado para a psiquiatria, apesar de, em sua maioria, ser esse o pedido inicial na procura pelo atendimento no serviço, tanto dos casos vindos de encaminhamento quanto em muitos casos de procura espontânea.

A qualidade do trabalho em Saúde Mental depende de muitas variáreis que não estão restritas às modalidades de atendimentos oferecidas. Muitos usuários não apresentavam demandas às quais a instituição pudesse dar continência. A falta de oficinas, ateliês, terapia ocupacional, atendimento familiar ou de recursos sociais (espaço culturais, recursos financeiros, espaços de socialização, etc.) apresentava-se como obstáculo no ato de encaminhar. Nem sempre os usuários chegavam ao PA "prontos", quando se tratava de demandas psicoterápicas, e nem sempre as demandas produzidas ou clarificadas vinham, como seria esperado, ao encontro dos recursos da instituição ou do município. Novas ofertas de atendimento precisariam ser construídas e isto também começou a ser discutido na equipe.

Pôde-se observar ainda, a partir da nova proposta de PA, que essa mudança provocou diferentes reações na equipe. A nova proposta entrava em contradição com o instituído, formando um novo campo de coerência, parecendo incorreto à forma já instituída. Como aponta Lourau, "todo novo espaço de saber entra em contradição com o saber instituído ..." (Lourau, 1993, p. 7).

Os serviços assistenciais de saúde devem ter flexibilidade para receber e trabalhar com a demanda dos usuários. É necessário criar canais de escuta e acolhimento das necessidades das pessoas, suas vontades e desejos.

A inter-relação de diferentes tipos de sofrimento produz, muitas vezes, uma compreensão mais abrangente das causas e conseqüências do adoecer psíquico. O grupo modifica seus integrantes e por eles é modificado. As múltiplas transferências criadas e o lugar em que cada um se coloca e coloca o outro permitem restituir, por sua vez, o outro e si mesmo às diferentes posições diante do desejo, mas nada garante que os grupos não se transformem em procedimentos burocratizados. É necessário atenção para o risco desta burocratização das nossas práticas, assim como para o perigo da cristalização das mesmas, não permitindo que o instituinte deixe de estar presente por "medo" de uma dissolução do instituído, ameaçando assim a identidade do profissional.

\section{BIBLIOGRAFIA}

BAREMBLIT, Gregório. (1992). Compêndio de Análise Institucional e outras correntes: Teoria e Prática. 3. ed. Rio de Janeiro: Rosas do Tempo, p. 152.

COSTA-ROSA, Abílio. (1987). Saúde Mental Comunitária. Análise dialética das práticas alternativas. Dissertação de Mestrado. USP. São Paulo.

COSTA-RosA, Abílio. (2000). O Modo Psicossocial. In. AMARANTE, Paulo (org.). 
Ensaios. Subjetividade, Saúde Mental, Sociedade. Rio de Janeiro: Editora Fiocruz,.

DOOR, Joel. (1994). Estrutura e Clínica Psicanalítica. Rio de Janeiro: Editora Taurus, .

LEVCOVITZ, Sérgio. (2000). Grupos de recepção ambulatorial: uma introdução ao tema. In: A Clinica da Recepção nos Dispositivos de Saúde Mental. Instituto de Psiquiatria. Cadernos IPUB, vol. VI no 17 2000, p. 21-29)

LOURAU, Renne. (1993). Renne Lourau na UERJ: Análise institucional e práticas de pesquisa. Rio de Janeiro: Editora UERJ.

LUZIO, Cristina Amélia. (1988). Pronto Atendimento. Boletim de Psicologia. Assis: UNESP/Dep. Psicologia Clínica, 1988, n 1, p.47-55.

OLIVEIRA, Raquel Corrêa. (2000). A recepção em grupo no ambulatório do IPUB/UFRJ. In: A
Clinica da Recepção nos Dispositivos de Saúde Mental. Instituto de Psiquiatria.Cadernos IPUB, vol. VI, nº 17 2000, p. 30-91).

QUINET, Antônio. (2000). As 4+1 condições da análise. RJ: Jorge Zahar Editora.

ROTELLI, F.; LEONARDIS, O. MAURI, D. (1990). Tradução de Fernanda Nicácio. Desinstitucionalização, uma outra via. In: NICÁCIO, F. (org.). Desinstitucionalização. São Paulo: Hucitec, 1990, p.17-59.

TENÓRIO, Fernando. (2000). Desmedicalizar e subjetivar: A especialidade da clínica da recepção. In: A Clínica da Recepção nos Dispositivos de Saúde Mental. Instituto de Psiquiatria. Cadernos IPUB, vol. 17, 2000, p. 80-91.

Recebido para publicação em 21 de agosto de 2003 e aceito em 25 de maio de 2004. 
